\title{
COMMENT
}

\section{IMPLICATIONS FOR LEGAL PROCEDURE OF THE FALLIBILTTY OF HUMAN MEMORY}

\author{
LAWRENCE S. KubIE, M.D. $\dagger$
}

\section{INTRODUCTION}

Various aspects of legal procedure are based upon a tacit assumption that a "normal" man can tell the truth if he tries. By implication this assumes that the major sources of error will be either a mechanical failure of the brain to record and reproduce past events, or else a deliberate desire to deceive or a reluctance to tell all. It will be my thesis that these assumptions are invalid: that in spite of every effort to be honest, the perceiving, recording, processing, reliving and reproducing of the events one observes and of the events in which one participates always are selectively colored; that these sources of error are ubiquitous; and that a relatively rare and minor role is played by those errors which are introduced by deliberate deceit, by mechanical limits of the brain as a recording apparatus or by organic brain damage. The disconcerting questions which these facts force upon us are (1) what role in legal testimony should be played by memory and by discrepanoies among the memories of different men, and (2) how are courts of law to proceed, since all testimony depends upon memory?

It should not cause dismay to discover that psychiatry can only raise these questions; it cannot answer them. Every doctor is familiar with this predicament. For centuries, before he could offer a cure he has had to diagnose fatal illnesses as "incurable." Yet he knew all along that he would never find a cure if he had not first recognized and acknowledged the existence of the disease. It is not strange then that all social and behavioral sciences such as the law must frequently acknowledge the existence of long-standing psycho-social "diseases" without immediately offering a remedy. This, however, does not justify complacency over existing methods of dealing with a situation on the grounds that they are "the best we've got." It should rather spur us on to find ways which are better.

$\uparrow$ Director of Training, Sheppard Pratt Hospital, Towson, Maryland. Member, Faculties of Yale University School of Medicine, College of Physicians and Surgeons of Columbia University, and New York Psychoanalytic Institute. A.B., 1916, Harvard University; M.D., 1921, Johns Hopkins University. 
The admonition to seek better ways is of particular importance in relation to the eliciting and evaluation of testimony, since testimony rests upon one of man's most fallible psychological instruments, his memory. Without pretending to be exhaustive I will list some of many ways in which memory is vulnerable. I will begin, however, by citing a comparable example drawn from another field.

A recent study was made of the process of supervision in psychotherapy and of the value of tape recordings for conducting supervision and studying the psychotherapeutic process. It was pointed out that we run counter to everything which we have learned about the processes of the memory when we expect a student conducting therapy to recall with precision what happened during a therapeutic session and to reproduce the session undistorted in a subsequent meeting with his supervisor. It is asking him to record and to recall without bias both sides of a rapid and free interchange in which he is a participant and not merely an observer, in which his own complex emotions are intricately involved, and in which he needs constantly to demonstrate his ability not merely to observe but also to guide that which he is observing and to predict that which is to come. In other words, he is asked to be a carefully disciplined pilot, a free reactor, a participant, an observer, a recorder, and an objective recounter, all without screening or bias. The patent absurdity of this demand was the starting point for the studies which were made with tape recordings. ${ }^{1}$

In one seminar a young psychiatrist reported that in a previous session his patient had suddenly asked that the recording machine be turned off because he was about to divulge some material which was particularly painful. The seminar group discussed the possible reasons for this, basing the discussion on their knowledge of the patient gained in previous meetings. To check the accuracy of their speculations the group suggested that the five or ten minutes of the therapeutic interview just preceding and following the interruption of the recording be played back. To the blank astonishment of the young psychiatrist and of the group as a whole, they heard the psychiatrist himself make the suggestion to the patient that the recording be interrupted. Of this fact the psychiatrist had not the slightest recollection. Yet from the material that preceded the interruption it became clear that the psychiatrist's intuition had served him well. He had sensed the patient's mounting tension. He had realized the need for some gesture of special consideration and privacy. The patient had responded with relief and after a few minutes had apparently suggested that the recording be

${ }_{1}$ See Kubie, Research into the Process of Supervision in Psychoanalysis, 27 PSYCHOANALYTIC Q. 226 (1958). 
resumed. Nevertheless, the psychiatrist had felt anxious lest he be criticized for his action; out of this anxiety had come the unconscious reversal of his memory of events and of the roles which he and the patient had played.

I should emphasize that these are friendly seminars in which the young psychiatrists do not feel assaulted by criticism. They value the opportunity to see themselves at work. Nevertheless, the fact that his own maneuver had been spontaneous, impulsive and in a sense unusual had aroused enough guilt and enough fear to make this earnest and able student unwittingly reverse his memory data. If this can happen under such friendly circumstances in an intimate postgraduate seminar, then surely we shall have to take account of similar phenomena in a court of law.

\section{The Psychopathology of Memory}

\section{Failure to Perceive, Record and Recall}

One function of psychiatry in relation to other disciplines is repeatedly to warn us away from the mistaken supposition that complex elements in human nature are simple. Accordingly one purpose of this article is to discuss the complexities of the processes of human memory and the implications of these complexities for legal procedure. Another is to provide a starting point for a search for more accurate and, therefore, fairer methods of evaluating the memories of witness, of accuser and of accused.

What we call "memory" actually consists of several components, each of which is vulnerable to distortion.

(1) Before there is anything to remember there must first have been a perceptual process. But even elementary perceptions are not simple acts of automatic registering. Perceptions themselves are selected under the influence of many processes of which the perceiver is unaware. Without realizing it we pick and choose among thousands of concurrent impressions. Moreover, in addition to the unaware selective influences which guide our perceptions we actually do a major amount of perceiving without awareness that we are perceiving at all. This is not an hypothesis. It is a fact that has been demonstrated repeatedly in experimental work, and which also is manifested daily in human life. The simplest experimental demonstration of the fact that we can perceive and record without being aware of it has been conducted with the use of a tachistoscope: a machine which flashes a visual image upon a screen for such a brief span of time that it is impossible for the individual to 
say what it is that he has seen; he can report only that it was "a flash of light with something on it." Subsequently however the influence of the image which was flashed upon the screen can be traced in spontaneous doodlings and drawings, in dreams, in word association tests and in such physiological components of emotional processes as changes in skin-temperature, color, sweat, resistance of the skin to the passage of a weak electrical current, and respiratory and heart rates.

Furthermore, innumerable examples can be adduced of people who have reproduced words, tunes and visual images which they have experienced without having noted at the time the fact that they had experienced anything out of the ordinary. For example, a young medical student seated at his desk by an open window hears a friend whistle to him from the street. This was a prearranged signal to go for a walk in the country. He approaches his friend whistling; yet what he whistles is not the tune he heard but another. Moreover, he is puzzled by the tune he is whistling; he cannot remember its name or where he has heard it. He whistles the tune to his friend, asking if he recognizes it. Thereupon the friend answers, "I was whistling that for half an hour and you paid no attention. I thought you must have gone out. Then I decided to try again; and this time I whistled another tune and you put your head out of the window."

In another instance the process of unaware selectivity operated under more obvious emotional influences. A young man encounters his psychiatrist at a Saturday night dance. In the course of the evening they pass each other repeatedly on the crowded dance floor. The young man looks at and through his analyst repeatedly, giving no sign of recognition. The psychiatrist thinks that the young man is embarrassed, and after one or two tentative smiles in his direction refrains from greeting him. On Monday morning the young man comes to his session and recounts a dream of having met his psychiatrist at a dance; he is unable to believe that the event had actually occurred.

Again, towards the end of her analysis a patient who is a poet dreams of topping a rise on a lovely hillside in spring and of seeing a valley full of straight, tall green flowers, their bells opening to the sky. She ends the description saying, "I have never seen anything like them." Then stopping and pointing at a lamp by the couch in the office she says, "How long has that been there? Those were the flowers." The lamp was a relatively new lamp, but it had been there for three weeks. The patient had walked by it every day of those three weeks and had looked at it from the couch, recording it and reproducing it in the dream as the poetic symbol of the approaching end of her treatment. Yet she had not known that she had seen it. 
What is more, if individuals are taken into a strange room and, upon being removed, are asked to write down everything that they remember seeing, one may write down twenty items, while another may recall fifty. But whether on his first trial one remembers few or many, if the same individual can then be put into a light hypnotic trance and be asked to write down everything that he saw in the room, he may be able to recall hundreds of additional items. Clearly he had registered and recorded them "preconsciously"; but he is not able to reproduce them until he is put into that half-way state between sleeping and waking, the state of "communicative sleep" which is called hypnosis.

In fact, thousands of simultaneous impressions, through eyes, ears, nose, tongue, skin, joints, muscles, apertures, and also from internal organs pelt us continuously. Some flick against insensitive areas, some against areas of emotionally sensitive concern. The sting of some of these will be recorded with pain but with precision. Others which touch off particularly pleasant sensations will subsequently be remembered with pleasure and with acuity. Still others which touch off pleasure will be buried because the pleasure was associated with guilt or with fear. Some which cause pain will be recorded and recalled with angry indignation; still other painful stings are buried and forgotten because of their setting of fear, guilt and shame. Therefore, in the mere perceiving and recording of such experiences emotional factors play an automatic selective role at the very moment of perception, thus determining the degree of awareness with which the individual, as a whole person, participates in the process of experiencing. Furthermore, things which are of major emotional importance to John may be of relatively minor importance to Tom. The one may record them with fair precision, while the other may record them only vaguely and diffusely, if at all.

From these reflections and from countless daily experiences and carefully controlled laboratory experiments, we must conclude that all human beings are subject to an incessant bombardment of sensory experiences and that often they will perceive and store these, process them internally (and what I mean by that I will describe below), bury or "forget" them, and reproduce them without ever knowing that they have experienced them. If they were asked whether they had ever seen such a lamp, had ever heard such a tune, had ever met their psychiatrist at a dance, they would answer quite honestly, "No." This means that one can be exposed repeatedly to an experience without conscious knowledge or awareness and without the ability to recall it to conscious awareness. Such a man will not be lying if he can recall some inconspicuous detail yet deny having seen some large and conspicuous 
object which was "right under his nose," even when a dozen other men recollect seeing it. Discrepancies of the sort are not rare or exceptional. Yet the same man may give many indirect indications that the experience had been recorded and "processed" on some lessthan-conscious plane; memory traces of the entire experience or of fragments of it could be elicited by appropriate experimental maneuvers. What implications this may hold for legal procedures, especially with regard to testimony and perjury, is a matter of grave concern.

The point is that the recording, storing and reproducing of experience (i.e., recalling it to conscious memory) are only in small part mediated by conscious processing, but are under the constant influence of highly selective preconscious and unconscious influences. Such preconscious perceptions make up the major share of the daily life of every human being; in fact, only a small fragment of our life experiences are mediated by conscious processing.

(2) Similar unconscious and preconscious mechanisms guide the storing and processing of experience. By this we mean the linking of one unit of experience to another, which in its primary steps depends upon the concurrence of more than one perceptual process in any unit of time. If it were ever possible to experience just one thing at a time, we would never be able subsequently to recall it. It would be like a railroad station in an empty field with no rails leading to or from it to link it to any rail system. In the nervous system the establishment of connecting links begins with the inevitable concurrent input of simultaneous events on a preconscious level. As Pavlov showed, a mere coincidence in time establishes these connecting links without which there could be no such thing as memory.

But this processing of experiences according to their relationships in time also determines our orientation in time and our time sense. Moreover, the concurrence of experiences juxtaposes them and makes possible that element of processing which compares, contrasts and groups them according to similarities, dissimilarities and contrasting elements. By means of such instantaneous comparisons we are enabled to classify experiences in categories and then to represent these categories by abstractions and memory images. It is this capacity to make quick comparisons of a present image with a past trace which makes it possible to remember faces, events, voices, gestures, places, and timesequences or time-intervals. Here again, although there is a component in this processing of perceptual experiences which is carried on consciously, the major share is carried on preconscionsly. And, as both Pavlov and Freud have showed, emotional processes whether conscious 
or unconscious also influence these connecting links and how they will be used.

(3) This processing and recombining of units of past experience make possible the re-experiencing or re-living of the past with varying degrees of vividness. The re-experiencing, again, may be broken down into a battery of interacting components. One may re-experience merely the sensory fragments of the past; a pain, an ache, a smell, a flavor, a color, a scene or a face may come vividly to mind almost as though it were present. Such sensory components of the past will combine in varying proportions with memory traces of the sensations received from the external surfaces of the body and limbs (exteroceptive) and from movements of muscles and joints (proprioceptive): sensations of heat and cold on the skin, and of moisture or dryness whether of the skin, eyes, mouth or other apertures, of flushing and blanching or the prickling sensations of the hair rising; also the movements of the face and of the muscles and joints of the trunk and limbs and the sounds of our own voices. In varying combinations these afferent elements contribute vivid sensory components to memory which make the past with all the feelings it evokes as vivid and real as though it were "here and now."

There are also the deeper components of sensation which come from within the body (enteroceptive). These make further contributions to the affective or "gut" components of our memories of the past. All of these enter into the re-experiencing of the past as though it were occurring in the present; but again none of the contributing elements need be conscious. These latent ingredients are ubiquitous in memory; although in most remembering, words are a short-cutting device which screens them out.

(4) This brings us to the usual re-experiencing of the past-as something which is represented largely by verbal symbolic clues. Actually this is the least vivid element in the total process of memory; it means remembering that something has happened to us, but almost as impersonally as though it had happened to someone else. Words here represent the past as from a safe distance, screening out all the more vivid sensory components of memory. Thus memory of this usual type actually involves a first step in dissociation and depersonalization. Yet it is to just this type that the word "memory" is usually restricted: namely, the memories which we represent by words. And these verbal clues to the past are themselves frequently experienced not accurately but with many unconscious distortions, as through the substitution of one memory for another or through the condensation of many similar experiences to represent them by one "memory." 
These, then, are the major components of memory: the perceptual components, the recording components, the processing components, the reliving components and finally the components of representation by means of verbal symbols. Each of these is vulnerable to distortions of several kinds: (a) by deliberate conscious misrepresentation; (b) as the result of subtle or gross organic changes in the central nervous system (for example, the memory defects of senility, arteriosclerosis, brain-damage, chronic alcoholism, infection); (c) by acute or chronic disturbances in the biochemistry of the body as a whole (as in toxic delirious states, hypoglycemic coma, drug effects); (d) by the influence of affective processes which may be represented by emotions of which we are fully conscious, but may also be sub-threshold processes sometimes even more potent than conscious emotions in their influence on the total constellation which comprises memory; (e) through the influence of variations in levels of participation (as in the difference between what we perceive or what we can relive or reproduce in sleep, in the waking states or under hypnosis) or (f) through the influence of those unconscious conflicts which are the origins of neurotic symptoms. Most of these sources of error are not deliberate. Yet deliberate falsifications of memory, denials of remembered facts, substitutions of altered facts are also possible and can be superimposed upon those guileless sources of error which are inherent in human memory. Consequently, errors are usually composite products of several of these processes.

Examples of such composite effects may be found in other types of behavior. A soldier in training camp who is pathologically afraid of his sergeant shoots himself in the foot. The act is deliberate but the fright and the lack of control are not. These are products of deep neurotic problems. The total constellation is a synthetic product of conscious, preconscious and neurotogenic unconscious processes.

A man of high caliber, creative in many ways and valuable to his community, is courageous, self-sacrificing, generous and meticulously honest in most human relationships, but is guilty of destructive and damaging behavior in his intimate life with women. In fact, he is almost incapable of telling women the truth. His father died and his mother remarried at a time in his life which was critical in his emotional development. Although in all other areas he is honorable, in this one area of deeply traumatic early experiences with mother, step-father, sister and nurse, he lies. Each such lie is deliberate and conscious. Yet his vulnerability to automatic lying in this one direction arises out of unconscious conflicts which had their origins in childhood fears and confusions. 
In spite of such complexities, each of which varies from individual to individual, the legal fiction remains that what one man remembers accurately another who has shared the experience must also rememberthat the one who claims to forget or who, thinking he remembers, reproduces an erroneous version of the incident experienced, is lying. I wish that the problem was as simple as this, but it is not.

What then are the facts? No one remembers all of any event. We do not remember the entire sequence of incidents which make up the event itself, nor all of the people involved, the entire setting-time, place and duration-nor the frequency of its repetition, nor the span of time covered by these repetitions. Yet in a court of law if there are discrepancies between the testimonies given by two men about some experience which they have shared, and if it is assumed or ascertainable that the testimony of one is more nearly accurate than is the testimony of the other, the more "correct" set of testimony is used as a measuring rod to test not merely the accuracy but also the veracity of the other man. This is an invalid test!

What is worse, the man who claims to remember most is usually thought of as the more honest. $\mathrm{He}$ is "telling all." The other is "holding back." This again is an indefensible assumption. No single testimony should become the measure of what both "should" or "must" recall. The failure to recall all that another claims to recall is not evidence that the less complete or less accurate version constitutes deliberate misrepresentation. In fact, instead of assuming that a less complete or less accurate report implies voluntary distortion, suppression, hiding, evading or deliberate misleading, any claims for total or precise recall should be regarded with equal suspicion, if not with more.

Therefore when in court anyone is asked, "Do you remember Jones? How many times have you seen Jones? When and where did you see Jones? Over how long a period have you known Jones?", discrepancies between the answers of two or more men cannot fairly or safely be used as a basis for charges of perjury. Anyone may give answers which are contrary to fact without deliberate lying. Of course he may be lying. Here is the rub. But he may also be answering the truth, insofar as the truth is accessible to him, when he says that he does not know whether he knows Jones, if and when they met, where they met, how often, or over how long a period the contacts between them were spread. To answer, "I do not know," or, "I cannot be sure," may be a deliberate deception or it may indicate a high determination to tell only the truth. And this is the case even when another man remembers or believes or pretends to recall far more about their joint experiences. 
In one emotional state multiple experiences can be fused and then be represented in memory as though they had been one event. This happens constantly in childhood, as when a child may recall as a single startling event something that may have happened a hundred times. This is one form of what is called technically a "screen memory." Every adult does this too. On the other hand, that same child or adult may recall one single event as though it had happened many times. This is another potential source of guileless discrepancies in juridical testimony.

There is a lesson to be learned here from mothers and their children. Mothers live close to the growing lives of their children. Yet unless they keep written daily diaries, few can reproduce accurately the dates and ages at which even the vitally important "firsts" occurred: standing, walking, talking, school, illnesses and even more highly charged events such as operations and accidents. Ask any pediatrican! Nothing is harder to be sure of than the answer to such retrospective "whens."

Finally, physical confrontation by another participant in a joint experience may act as a trigger, starting a flow of impulses along associative pathways leading to a more complete reproduction or recollection of events, yet never necessarily uncovering them fully. This need not always happen; but whether it happens or not does not carry any necessary implication of deception.

These are only a few of the facts about memory and the tricks it plays on all of us all the time, even when individuals are trying their best to remember with accuracy and even in the absence of organic brain disease. Under such circumstances to ask, "Do you or do you not remember?", to take the answer as indicative of the truthfulness or dishonesty of the man who answers, and then to use an inaccurate answer as a basis for an accusation of perjury is, to say the least, dangerous. It violates clinical and experimental knowledge that has been gained in the last seventy-five years. As a matter of fact, the knowledge of this goes back even further. The great Charles Darwin wrote that he had discovered that if he did not write down the observations which argued against his theories he always forgot them. He was not trying to fool a court. But the conscious components of memory were operating selectively under the influence of profound emotions. If this happened to Darwin it can happen to every man, and our legal procedures must learn how to take it into account.

\section{False Memories}

Up to this point we have considered only those distortions of memory which manifest themselves in general memory losses or in 
special gaps or lapses. We have not included those false memories which can arise as symptoms of the processes of mental illness and whose potential influence must also be evaluated. Otherwise, discrepancies between true and false memories may be wholly misleading to judge and jury.

A few types and settings of such false memories may be noted as examples. First, there are the stories which are made up out of romantic, tragic, heroic or sympathy-compelling fantasies by men who are slowly and imperceptibly losing their ability to distinguish between their daydreams and reality. Such a man is described by Lord Dunsany in the story entitled "The Strange Case of Mr. Shad." This is a not infrequent phenomenon in the incipient phases of a schizophrenic illness. In less fantastic forms it also plays a greater role in human life than is usually realized. Nor are all such romances made up consciously. Many arise for subtle and insidious reasons.

In certain situations these pseudological, carefully-thought-through fantasies, called in their more extreme, elaborate and recurrent forms "pseudologia fantastica," can assume quite realistic forms. They need not be so extravagant as to be easily recognized. They can be mere extrapolations from factual to imaginary experiences. Sometimes they are as purposeless as is the kleptomania of the millionaire; but they can also serve vicious, destructive and vengeful purposes.

Then there are the confabulations which people introduce to cover gaps in memory. This is likely to happen when organic brain disease has caused memory difficulties which are embarrassing but into which the patient has insight and about which he is chagrined. He may then fill in with made-up data which will sometimes consist of simple, plausible anecdotes. A patient who has not been out of a hospital for months may give a detailed account of a walk down the street, the friends he met, the meals he ate, the movie he attended. These confabulations can occur in the setting of any organic memory deficit, but are characteristic of the condition known as Korsakow psychosis, which arises not exclusively but most frequently among severe chronic alcoholics with damage to certain areas of the brain.

Or such false memories may falsify only the frequency of some event. In expansive moods five may become fifty, whereas in depressed and shrunken moods fifty may be recalled as five. This misuse of the decimal place need not be deliberate; it may occur as unconsciously as it does in dreams.

Then there are the retrospective falsifications which are one of the hallmarks of the fully developed paranoid condition. The man who has delusions that he is being persecuted may feed those delusions by false 
memories of imaginary, yet possible, experiences with which he attempts to prove to himself and to others the truth of his suspicions. A gesture fifteen years ago by a stranger across the street, although not understood at the time, suddenly becomes a signal from "them" that they are going to take over and control his thoughts. Then comes a series of ten, twenty, thirty examples of similar imaginary episodes all told in minute and precise detail. Such accusations may have for the accuser the quality of real experiences, as though he had dreamed them while awake and without ability to distinguish between his fantasies and reality. Or they may be conscious and deliberate and malicious lies.

Since in this setting the delusions of persecution may give rise to intense hatred, the hate may color the retrospective falsifications so that they become counter-accusations. Thus, false accusations may rest on false memories, yet have much of the color of reality and be told with intense feeling and apparent realism. Such false memories feed the need for vengeance which not infrequently occurs in the paranoid personality or the paranoid psychosis. The testimony of the recent and repentant convert from Communism should be regarded with special suspicion along these lines: he may be particularly eager to involve others in his confessions in an effort to win favor and to clear his own skirts, or out of the very illness which determined his original hatreds. The "conversion" did not eliminate hatred from his soul; it just changed the target.

There are also the false memories of those who need to make sacrifices to expiate either rational or irrational guilt feelings. Some of these unhappy people offer themselves up as sacrificial victims, as for instance, the man who is laden with delusions of guilt and who gives himself up to the police for a murder he could not possibly have committed. And some, in addition, must make sacrifices of other human beings. Paradoxically enough, sometimes those who are most heavily burdened with guilt may develop a pathological need to make a human sacrifice of someone else, as though they could expiate their own guilt by offering someone else upon the altar of the gods. They may sacrifice those to whom they are close, with whom they may actually have been associated, with whom they may imagine that they have been associated or with whom they may have longed to be associated but by whom they were rejected. The need to sacrifice another human being at the altar of one's guilt-laden conscience is one of the difficult sources of memory distortion which enter into all cases in which someone who has confessed guilt of past crimes turns and accuses others, whether of private offenses, criminal acts or acts of treason and subversion. This intro- 
duces a disturbing element of doubt as to the dependability of all such testimony.

\section{The Fallibility of Memories of Judge, Attorneys, and Jurors}

Although I have so far discussed only the memory of the testifying witness, we must not overlook the fact that this is only part of the story. We must consider also the memories of the judge, of the attorneys for both the prosecution and the defense, and of the jurors: what they recall of everything that transpires in the courtroom is not to be taken for granted. Yet we do take it for granted. We assume the accuracy of the court stenographer's perceptions and of his recording of his percepts. We assume that judges, attorneys and jurors as well perceive and record accurately. Yet "accurately" implies more than a court stenographer's transcript. It implies voice and intonation and manner and expression.

It would be possible to subject all of these assumptions to test. We no longer need to depend upon unaided memory. Testimony can now be taped and screened. The judge, the attorneys, and the jury could study the taping and the screening of the testimony, studying it over and over if necessary to catch nuances of voice, expression and gesture. It was not possible to do this until recent years, but it is possible today, and without too great expense. One wonders how much error and how much honest disagreement could be eliminated by the use of such simple devices alone. One wonders also how much error of interpretation could be eliminated if the triers had more than a single fleeting chance to study, observe and listen to a witness as he gives his testimony: to study his voice and manner not once but repeatedly by replaying his recorded testimony, watching for possible tell-tale hints of falsification, confusion, dissimulation and confabulation.

And if for a moment we consider the processes of appeal, how illuminating would be an appeal based upon a re-examination of the taped and screened record of the original proceedings! To demonstrate the actual behavior of trial participants, judge, attorneys and jury might well reveal more than the tidied-up or slanted versions of recorded percept or of memory.

I do not for a moment pretend to offer solutions to any of the problems I have raised. I am suggesting only that devices are available today which, properly applied, could make a court into an instrument of objective inquiry and which might free it from some of the errors of the past. But this will not be done so long as we are complacent about the dependability of honest memory, for memory remains immensely 
fallible even when every effort is made to tell the whole truth and nothing but the truth. Let me, therefore, end by giving a few examples of the kinds of inter-disciplinary research which might illuminate some of these unsolved issues.

\section{Experimental Approach}

I will not attempt here to review systematically all the possible experimental approaches to these problems. I will limit myself to a few illustrations of investigations which might be fruitful. In all of these studies the design is essentially simple and constant: to attempt to record for minute study the unintended ingredients in speech, expression, manner and mannerism of accuser, accused, witness, judge, attorneys, and jurors. This would be done preliminarily in artificial facsimiles of legal processes and subsequently in screenings and recordings of actual courtroom proceedings with the first objective of ascertaining whether these would provide dependable indices of deliberate deception as opposed to unconscious and involuntary error. A second objective would be to test the accuracy of memory and its reproduction under experimental situations. For these purposes it would be necessary to collect a large and varied array of old cases with complete stenographic records. These would have to be of three kinds: (a) cases in which judge and jury had made definite decisions the accuracy of which had been confirmed by subsequent developments over the years; (b) cases in which the accuracy of the judgments had been disproved over the course of years; and (c) cases in which for one reason or another, inability to reach any decision had resulted in dismissal. These records of old cases would be used as scripts for a series of mock trials in which a certain number of witnesses would be schooled to give honest and accurate answers upon direct and crossexamination. Other witnesses would be falsely instructed, so that they would give honest but misleading answers. A third group would be instructed to give consciously false answers. The behavior and speech of all would be recorded and screened. ${ }^{2}$

From these recordings and films, it should then be possible to study the processes of deception by comparison of the behavior of those persons who are giving answers which they know to be true with the

2 A similar experimental paradigm might be appropriate to an investigation of the role of the attorney in the trial process. In an adversary system it is the attorney's duty to present his case in a form which is as favorable as possible to his client. Inevitably, this produces a certain amount of slanting. If we are to test the assumption that an adversary system is the best system by which to approximate truth in legal procedures, then we should compare the results achieved in mock trials in which some attorneys "advocate," while others present their case in a non-partisan manner. 
behavior of those whose answers they alone know to be false, under circumstances where the veracity of each is under suspicion. It would be possible to create greater emotional impact in this situation by promising sizable rewards to those witnesses who succeed in convincing judge and jury of their truthfulness: both to those whose deliberate deceptions are not detected and to those whose "true" testimony is believed. Then, by the repeated study of pictures, sometimes in slow motion, an appraisal of every aspect of speech, posture, facial expression, hand-gesture, eye-movements, breathing, etc., might be made.

The basis of such studies is in sharp contrast to the basis of the so-called lie detectors. The principle of these latter consists in an erroneous assumption:- that there is a specific relationship between any one emotion and those autonomic discharges which are connected with emotional states. In reality an individual can have the same autonomic discharge when he is telling the truth under stress as when he is telling a lie under stress. It is not the truth or the lie but the stress, common to both, which is linked to emotional processes. On the other hand, there are organs other than those of speech by which we do communicate meaning to the outside world, mainly preconsciously-eyebrows, nose, eyes, the skin of our cheeks, mouths, hands, fingers, breathing. These organs of communication have never been adequately studied. There are a few slow-motion pictures of the apparently random repetitive movements of children which have shown that at least in a high proportion of instances the movement is in fact not random, but has a clear and transparent meaning which becomes understandable only if the picture is run slowly enough so that one can analyze the movements in detail.

When a judge, attorney or juror observes a man who is testifying, he normally concentrates primarily on the face and eyes. From the rest of the witness' body he receives only a few hints. As a result much of the unspoken language is unseen and unheard; it is like the four rings in a five-ring circus that go unseen because one is focussing all attention on the center ring. This is familiar to all of us. It is this tendency which the stage magician exploits by drawing the attention of the audience to one hand so that they will not notice what the other hand is doing. This we do automatically as we observe witnesses. But until systematic screenings and tape recordings of witness behavior are studied it will be impossible for anyone to predict to what extent telltale indications of deception or of dissimulation or of partial truth may be discernible from this body language with statistically greater accuracy than words alone provide. 
After studies are made of these processes of communication in such facsimile situations, it should be possible to make similar recordings and similar screenings of the behavior of witnesses in actual court proceedings, not for the public press or for the public consumption, but for further experimental investigation. With the help of infra-red film it should be possible to do this without flooding the courtroom with excessive lighting.

A next step in such an investigation would be to contrast the results of direct and cross-examination conducted in open courtroom with the results of direct and cross-examination in isolated, tête-à-tête interviews in which total recording by tape and film is made. In the past it was impossible to preserve a full record of an interview other than by reliance on the fallible percepts and memory of the court stenographer. Therefore there were good reasons for examining an individual only in the open courtroom: the possibilities of intimidation or bribery which might occur in a closed interview cast constant doubt as to the validity of testimony elicited tête-à-tête. But when a closed interview is conducted in a special room wired for sound and lighted for screening, a total record of everything that transpires can be secured; and it should be easy to make further provision to assure against subsequent tampering, through procedures insulating the recording machines and their product.

I would emphasize again my earlier statement that these suggestions are intended only to illustrate some of the types of investigation which might be undertaken by a multi-disciplinary team of lawyers, clinical psychologists and psychiatrists and which might be expected to throw light on some of the problems of juridical testimony. We will not attempt to describe here the kind of research institute in psychiatry and legal procedure which would be needed to staff, finance and conduct such investigations.

I cannot close this section on the experimental approach without emphasizing again the importance of studying the process of appeal by similar devices. Appeals based on astute arguments from the cold record by partisan advocates are one thing. Appeals based on the actual study of recordings of court procedures might be quite another. The devices which I have described in this section would make possible a direct study by appellate judges of the relevant behavior of all parties to the trial. A systematic comparison of the outcome of such appeals as conducted in these two ways should not be postponed indefinitely.

Finally, research into the procedures by which testimony is elicited and evaluated must include basic research on processes of speech. Yet words are only one ingredient in the communication and disguise of 
thoughts and feelings. Their implications are subject to subtle modulations which are expressed by variations in volume, pitch, intonation, pronunciation, stress, rhythm, voice placement, resonance, such affective elements as hints of moaning, groaning, whining, smiling, and the rhythmical or arhythmical grouping of words into word clusters with silent gaps or into a continuous and unmodulated stream. For such studies precise registration will be needed of decibels of volume, of time intervals, and even of the motion of the air-volume in breathing and in speech. These modulations are themselves so brief and follow each other so swiftly that the duration of many of them approximate the subliminal durations used in tachistoscopic experiments. Consequently, the perception of them depends upon preconscious recognitive processes and constitutes another example of the fact that in language there is a stream of preconscious processing of which words provide only a fragmentary conscious sample. In addition to words, patterns of mimetic facial and body movements constitute the para-linguistic components of language. These components, explored under the term kinomorphic analysis, are charged with potentially ascertainable meaning.

Because it is artificial to isolate any one of these elements from the total technique of communication, analysis of language and of the multiple components of the communicative process as it operates in direct and cross-examination conducted both in the courtroom and in isolation will be an important element in the studies carried on by any law school which wants not merely to teach what has been practiced in the past but also to find new and better ways for the future. This will add new dimensions to the studies which will engross investigators who explore the processes of law in the future.*

* Certain references will serve as leads into the literature: 1 \& 2 RAPAPORT, Diagnostic Psychological Testing (Menninger Clinic Monograph Series Nos. 3 and $4,1945,1946$ ) (the data on memory, retention, recall and reproduction appear in many places throughout these two volumes); RAPAPORT, EMOTIONS AND MEMORX (2d ed. 1950); Wechsler, The MeAsurement and Appratsai of Adult INTELLIGENCE (4th ed. 1958) ; Birdwhistell, Background to Kinesics, 13 ETC.: A REVIEW of General Semantics 10 (1955); Birdwhistell, Introduction to Kinesics, Dept. of State, Foreign Service Institute, 1952. 